\title{
Vector-Field Visualization of the Total Reflection of the EM Wave by an SRR Structure at the Magnetic Resonance
}

\author{
Magdalena Budnarowska *(D), Szymon Rafalski and Jerzy Mizeraczyk (D) \\ Department of Marine Electronics, Gdynia Maritime University, Morska 83, 81-225 Gdynia, Poland; \\ szymonxrafalski@gmail.com (S.R.); j.mizeraczyk@we.umg.edu.pl (J.M.) \\ * Correspondence: m.budnarowska@we.umg.edu.pl
}

check for updates

Citation: Budnarowska, M.; Rafalski, S.; Mizeraczyk, J. Vector-Field Visualization of the Total Reflection of the EM Wave by an SRR Structure at the Magnetic Resonance. Energies 2022, 15, 111. https://doi.org/ $10.3390 /$ en15010111

Academic Editor: Antonino S. Aricò

Received: 9 November 2021

Accepted: 18 December 2021

Published: 24 December 2021

Publisher's Note: MDPI stays neutral with regard to jurisdictional claims in published maps and institutional affiliations.

Copyright: (C) 2021 by the authors. Licensee MDPI, Basel, Switzerland. This article is an open access article distributed under the terms and conditions of the Creative Commons Attribution (CC BY) license (https:// creativecommons.org/licenses/by/ $4.0 /)$.

\begin{abstract}
Metamaterials are artificially structured composite media with a unique electromagnetic (EM) response that is absent from naturally occurring materials, which appears counterintuitive and aggravates traditional difficulties in perceiving the behavior of EM waves. The aim of this study was to better understand the interaction of EM waves with metamaterials by virtual visualizing the accompanying physical phenomena. Over the years, virtual visualization of EM wave interactions with metamaterials has proven to be a powerful tool for explaining many phenomena that occur in metamaterials. In this study, we performed virtual visualization of the interaction of an EM plane wave with a split-ring resonator (SRR) metamaterial structure, employing CST Studio software for modeling and comprehensive simulations of high-frequency EM fields of 3D objects. The SRR structure was designed to have its magnetic resonance at the frequency $\mathrm{f}=23.69 \mathrm{GHz}$, which is of interest for antennas supporting wireless microwave point-to-point communication systems (e.g., in satellite systems). Our numerical calculations of the coefficients of absorption, reflection, and transmission of the EM plane wave incident on the SRR structure showed that the SRR structure totally reflected the plane EM wave at the magnetic resonance frequency. Therefore, we focused our research on checking whether the results of numerical calculations could be confirmed by visualizing the total reflection phenomenon on the SRR structure. The performed vector-field visualization resulted in $2 \mathrm{D}$ vector maps of the electric and magnetic fields around the SRR structure during the wave period, which demonstrated the existence of characteristic features of the total reflection phenomenon when the EM plane interacted with the studied SRR, i.e., no EM field behind the SRR structure and the standing electric and magnetic waves before the SRR structure, thus, confirming the numerical calculations visually. For deeper understanding the interaction of the EM plane wave with the SRR structure of reflection characteristics at the magnetic resonance frequency $\mathrm{f}=23.69 \mathrm{GH}$, we also visualized the SRR structure response at the frequency $\mathrm{f}=21 \mathrm{GHz}$, i.e., at the so-called detuned frequency. As expected, at the detuned frequency, the SRR structure lost its metamaterial properties and the obtained 2D vector maps of the electric and magnetic fields around the SRR structure during the wave period showed the transmitted EM wave behind the SRR structure and no EM (fully) standing waves before the SRR structure. The visualizations presented in this study are both unique educational presentations to help understand the interaction of EM plane waves with the SRR structure of reflection characteristics at the magnetic resonance and detuned frequencies.
\end{abstract}

Keywords: SRR structure; frequency selective surfaces; subreflector; split-ring resonator; metamaterials; electromagnetic field; metamaterial unit cell; computer visualization; electromagnetic coupling; CST Studio

\section{Introduction}

Metamaterials have been an attractive research topic for many years due to their unusual electromagnetic (EM) properties and possibilities for wide applications. In 2003, metamaterials were recognized by the Science journal as one of the top ten scientific breakthroughs of the decade [1]. 
Metamaterials are a group of structures with EM properties not found in nature. Unusual properties of metamaterials include a negative refractive index, inverse Doppler effect, opposite directions of the group and phase velocity vectors of the wave, and an increase in EM wavelength with increasing frequency.

The building blocks of a metamaterial are structural units, also known as unit cells [2,3]. From unit cells, larger metamaterial structures are created in two-dimensional form, called metasurfaces, and three-dimensional form with a defined spatial geometry.

The EM properties of metamaterial structures depend mainly on their shape, geometry, size, and material parameters, as well as the ratio of the specific size of a single structural unit to the EM wavelength. The metamaterial effect occurs when the dimensions of the structural unit are significantly smaller than the EM wavelength with which the structure interacts [4].

Numerous studies are found in the literature describing resonant metamaterial structures and their properties of absorption [5-13], reflection [14-18] and transmission [19-22]. Due to their unusual characteristics, metamaterials have found applications such as EM energy absorbers (so-called harvesters) [23-26], super lenses [27-29], filtering devices [30,31], sensors [32,33], optical modulators [34,35], slow light devices [36], cloaking devices [37,38], detectors [39,40], and antenna elements [41,42], among others.

In this study, we numerically investigated the reflection properties of a selected SRR structure for its suitability as a subreflector in an antenna used for a wireless point-to-point microwave communications system [43-45]. Such systems operate in narrow frequency bands ranging from 18 to $30 \mathrm{GHz}$ (K-band and Ka-band). One such band is the licensed $23 \mathrm{GHz}$ band covering the range of 22-23.6 GHz [46]. Wireless microwave point-to-point communication systems are also used in cell phone systems providing transmission between a base station and the base station controller. Antennas used in wireless point-to-point systems feature strong directional radiation characteristics and high energy gain [45].

The SRR metamaterial structure we selected is in the form of a metasurface composed of single SRR (split-ring resonator) cells [47-51]. We designed the SRR material structure with geometrical parameters such that its magnetic resonance (magnetic permeability $\mu<0$ ) demonstrated, among other things, that total reflection of the EM radiation incident on the SRR structure occurred at a frequency of about $23 \mathrm{GHz}$, i.e., the frequency band of antennas supporting wireless microwave point-to-point communication systems (e.g., satellite systems). Due to its total reflectance of the EM radiation, this SRR metamaterial structure could find application as a subreflector of EM radiation in these types of antennas. The purpose of the subreflector is to focus the radiation reflected from the antenna dish. Then, this radiation is reflected from the subreflector to the converter, providing excellent reception quality [44].

Here, we present the results of numerical studies on the behavior of the selected split-ring resonator (SRR) structure with a magnetic resonance frequency about $23 \mathrm{GHz}$. In particular, the study was focused on the total reflection of an EM plane wave by the SRR structure. Numerical simulations were performed using the CST Studio software package. The numerical calculations of the coefficients of absorption, reflection, and transmission of the EM plane wave incident on the SRR structure showed that the SRR structure strongly reflected the EM plane wave at the magnetic resonance frequency. To better understand the interaction of the EM plane wave with the studied SRR structure, we used virtual visualizing of EM wave interactions with metamaterials, which, over the years, has been a powerful tool for explaining many phenomena occurring in metamaterials, for examples see [52-55]. We performed a vector-field visualization that resulted in $2 \mathrm{D}$ vector maps of the electric and magnetic fields around a SRR structure during the wave period, which demonstrated the existence of characteristic features of the total reflection phenomenon when the EM plane wave interacted with the studied SRR, i.e., no EM field behind the SRR structure and the standing electric and magnetic waves before the SRR structure, thus, confirming the numerical calculations visually. We also visualized the SRR structure response at the frequency $\mathrm{f}=21 \mathrm{GHz}$, i.e., at the so-called detuned frequency. The obtained 
$2 \mathrm{D}$ vector maps of the electric and magnetic fields around the SRR structure during the wave period showed that, at the detuned frequency, the SRR structure lost its metamaterial properties. The visualizations presented in this study are both new and help to understand the interaction of EM plane waves with the SRR structure of the reflection characteristics at the magnetic resonance and detuned frequencies. The presented results for the simulation of an EM plane wave interacting with an SRR metamaterial structure include the frequency characteristics of absorption, reflection, and transmission of the EM wave; the effective composite electrical permittivity; and magnetic permeability describing the EM properties of the studied structure.

\section{Metamaterial Unit Cell}

A typical single SRR metamaterial cell for building metasurfaces is a metal ring with a gap, i.e., a so-called magnetic resonator from an electromagnetic point of view [38]. Placing such a metal ring in an oscillating EM field induces an oscillating current in the ring and a corresponding changing polarity at the surfaces of the gap. The oscillations depend on the inductance of the ring and the capacitance of the gap. In this situation, the metal ring with a gap can be considered to be an LC circuit, characterized by a resonant frequency. The resonance depends on the alignment of the magnetic and electric field vectors, and hence the direction of propagation of the incident EM wave relative to the SRR structure. The magnetic resonance in the SRR is excited by the magnetic field of the incident EM wave if the external magnetic field $\mathrm{H}$ is perpendicular to the SRR plane; this imposes that the EM wave is propagated in a direction parallel to the SRR [56].

The plane wave propagates in the $+x$ direction, implying boundary conditions in the CST Studio software package. A perfect magnetic conductor boundary condition (Figure $1 \mathrm{~b}$, $\mathrm{Et}=0$ ) is defined along the walls of the $\mathrm{z}$-axis (correspondingly, the magnetic field strength vector $\mathrm{H}$ is directed in the $+\mathrm{z}$ direction) and perfect electric conductor boundary condition (Figure $1 \mathrm{~b}, \mathrm{Ht}=0$ ) along the wall of the $\mathrm{y}$-axis (correspondingly, the electric field strength vector $\mathrm{E}$ is directed in the $+\mathrm{y}$ direction).

a)

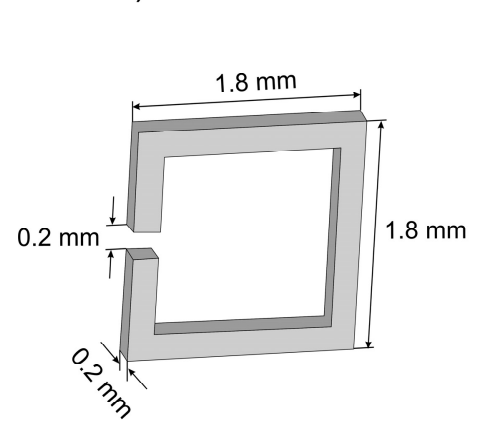

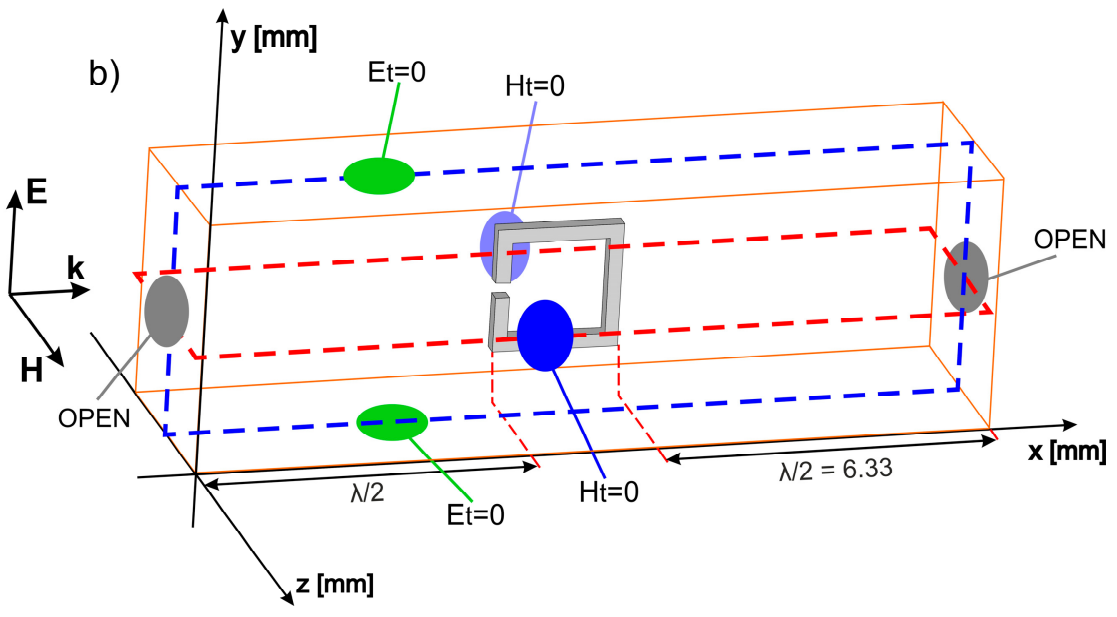

Figure 1. The geometry of the SRR resonator (a) and the computation area (marked in orange lines) with the boundary conditions (b). The electric field strength vector $E$ of the incident electromagnetic wave is directed in the $+\mathrm{y}$ direction. The magnetic strength vector $\mathrm{H}$ is directed in the $+\mathrm{z}$ direction.

In our study, the single SRR metamaterial cell was a square metal ring (Figure 1) made from a material with infinite conductivity (called a perfect electric conductor (PEC)). The cross-section of the ring was a square with sides of $0.2 \mathrm{~mm}$. The arm length of the ring was $1.8 \mathrm{~mm}$. A $0.2 \mathrm{~mm}$ gap was made in the middle of one arm. The summed length of the SRR resonator arms was half a wavelength $(\lambda / 2 \approx 6.33 \mathrm{~mm})$ of the frequency at which the magnetic resonance occurs (in our case at $\mathrm{f}=23.6 \mathrm{GHz}$ ). 
The SRR unit cell was placed symmetrically in a computational cell with the dimensions: $\mathrm{x}(0 \mathrm{~mm},+14.46 \mathrm{~mm}) ; \mathrm{y}(0 \mathrm{~mm},+3.8 \mathrm{~mm}) ; \mathrm{z}(-3.2 \mathrm{~mm}, 0 \mathrm{~mm})$ (see Figure $1 \mathrm{~b})$. The computation area $(14.46 \times 3.8 \times 3.2 \mathrm{~mm})$ is marked with black lines in Figure 1 . The front of the computation area is set to $\mathrm{z}=0$.

\section{Simulation Procedure}

The numerical simulation for the vector visualization of the interaction of EM wave with the SRR structure was performed using CST Studio software equipped for modeling and comprehensive simulations of high-frequency EM fields of 3D objects [57]. This environment uses the finite element method (FEM) and method of moments (MoM) in the frequency domain to solve EM field problems.

The simulation process had two objectives:

1. Determining from the results of a scattering matrix $S$, the coefficients for absorption, transmission, and reflection, as well as the effective composite electric permittivity and magnetic permeability of the studied metasurface,

2. Determining the electric and magnetic field distributions in 3D space bounded by the computation area defined in CST studio.

The simulation procedure for visualizing the interaction of the EM field with the SRR structure involved modeling a single SRR structure in a computational cell, and then multiplying it along the $y$-axis and $z$-axis to obtain information about the studied metasurface.

We proceeded to simulate the response of the examined SRR structure to an EM plane wave in the frequency range 15 to $30 \mathrm{GHz}$. The plane wave (see Section 4) was placed in the input plane of the computational cell at $x=0 \mathrm{~mm}$, propagating in the $+x$ direction. The length of the computational cell in the $x$-direction covered half a wavelength $(\lambda / 2=6.33 \mathrm{~mm})$ both before and after the SRR structure (see Figure $1 \mathrm{~b}$ ).

The simulation involved performing numerical calculations using a Frequency Solver. The application of the Frequency Solver enabled simulations using excitation with a sinusoidal signal of a given frequency. Consequently, it was possible to obtain distributions of electric and magnetic fields for selected frequencies.

In order to determine the characteristics of the effective composite electric permittivity and magnetic permeability, a module in CST Studio using the Nicolson-Ross-Weir algorithm was used [58-60]. This algorithm enables the determination of the composite electric permittivity and magnetic permeability based on the obtained coefficients of a scattering matrix and the dimensions of the analyzed structure [60].

As a result of the numerical simulations, we obtained the distributions of electric field $\mathrm{E}$ and magnetic field $\mathrm{H}$ in the 3D space bounded by the computational area defined in CST Studio (marked by black lines on Figure 1).

In this paper, we present the calculated characteristics of the effective composite electric permittivity and magnetic permeability for the metasurface made of SRR unit cells; the absorption $\mathrm{A}$, reflection $\mathrm{R}$, and transmission $\mathrm{T}$ coefficients of the metasurface; and the changes, during one wave period, of electric and magnetic field distributions in the xy plane for $z=-1.6 \mathrm{~mm}$ (blue dashes, Figure $1 \mathrm{~b}$ ) and in the $x z$ plane for $y=1.9 \mathrm{~mm}$ (red dashes, Figure 1b), respectively. The main novelty of this study is in the 2D images of the distribution of the electric and magnetic fields during a single wave period. These images visualize the interaction of the EM wave with the SRR metasurface in two cases: at the magnetic resonance frequency and at a detuned frequency.

\section{Parameters of the Incident Electromagnetic Plane Wave}

The strengths of the electric and magnetic fields in the incident EM plane wave followed a Gaussian distribution with maximum amplitudes of $1.106 \mathrm{~V} / \mathrm{m}$ and $2.68 \cdot 103 \mathrm{~A} / \mathrm{m}$, respectively. The remaining parameters of the plane wave pulse (Figure 2) were as follows: maximum pulse power density, $2.68 \mathrm{GW} / \mathrm{m}^{2}$; full width at half maximum (FWHM), $\tau=0.0268 \mathrm{~ns}$; pulse rise time, $\tau_{r}=0.0192 \mathrm{~ns}$; pulse fall time, $\tau_{f}=0.0192 \mathrm{~ns}$. 


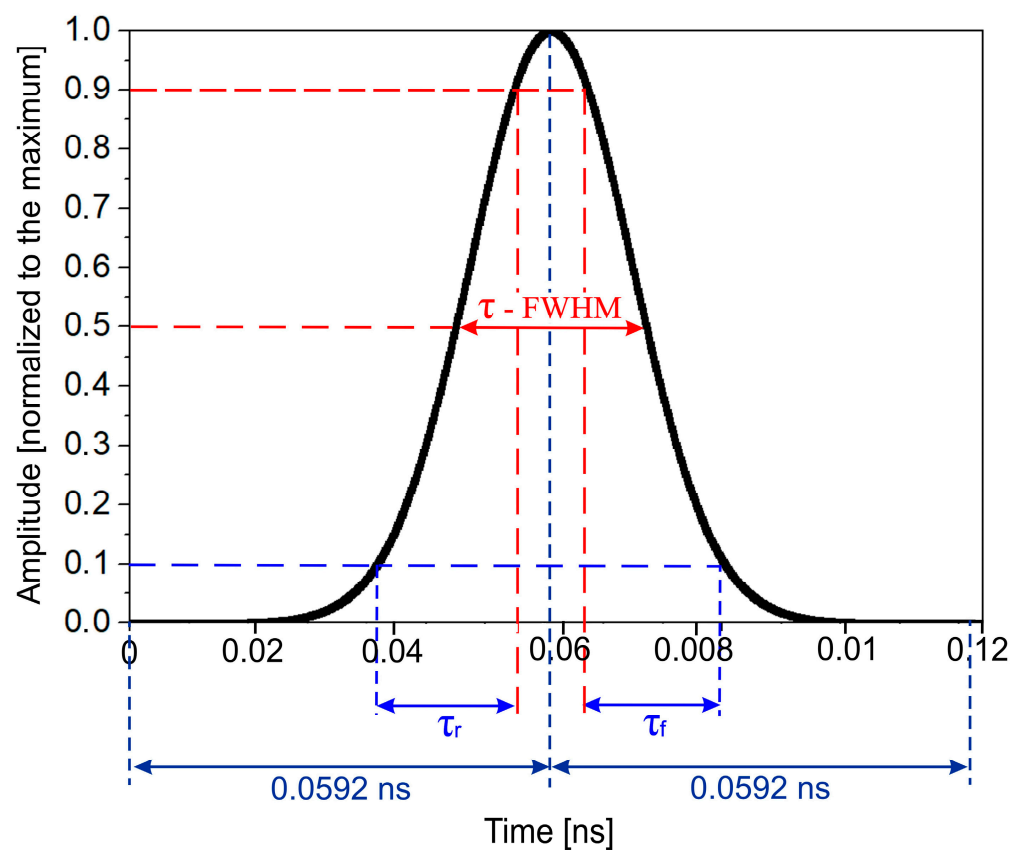

Figure 2. The normalized amplitude of the electric field strength (or the magnetic field strength) of the incident Gaussian EM plane wave as a function of time.

\section{Results}

Figures 3 and 4 present the characteristics of the effective composite electric permittivity and magnetic permeability coefficients in the frequency range of $15-30 \mathrm{GHz}$, as determined in the CST module using the Nicolson-Ross-Weir algorithm. The effective parameters of the metasurface are extracted from the S-parameters. It is observed that composite magnetic permeability changes dramatically at the resonance frequency. The imaginary part of composite magnetic permeability represents a strong reflection to the incident EM wave. The figures show that the negative value of the real part of the composite magnetic permeability $\mu^{\prime}$ occurs at $23.69 \mathrm{GHz}$; this is a characteristic of split-ring resonators at the magnetic resonance frequency $[61,62]$.

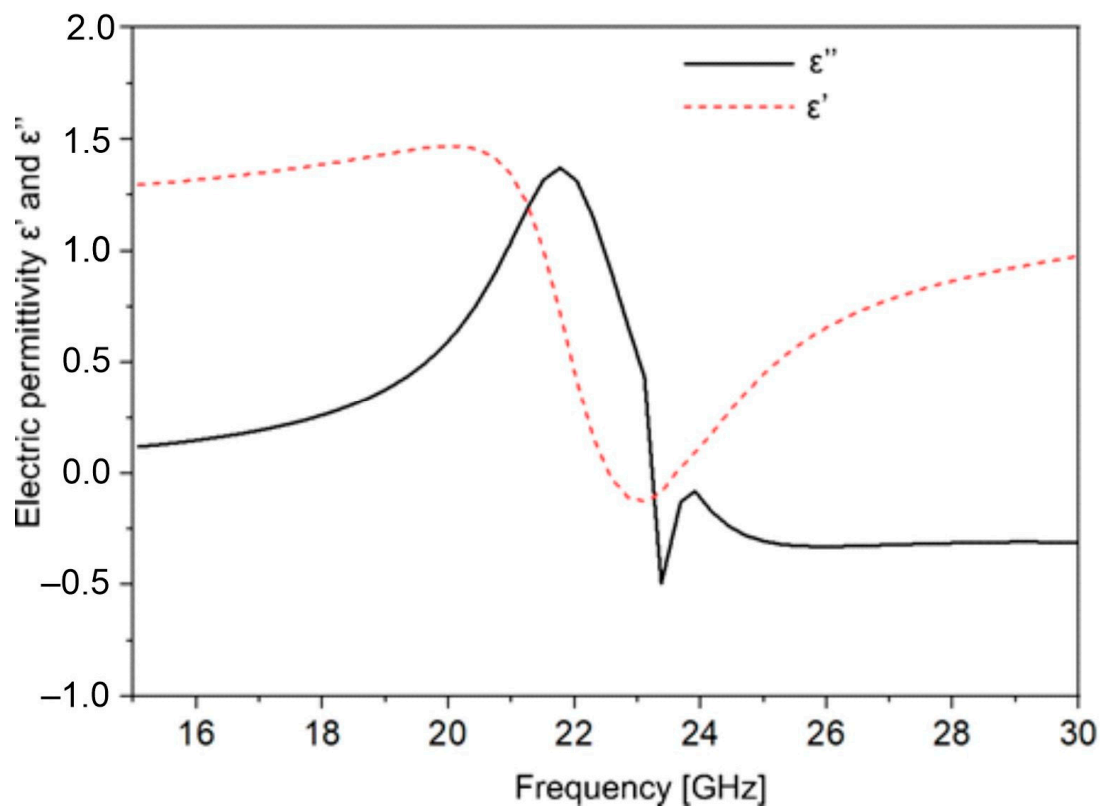

Figure 3. Frequency characteristics of the composite electric permittivity of the tested SRR structure ( $\varepsilon^{\prime}$ and $\varepsilon^{\prime \prime}$, the real and imaginary parts of the effective electric permittivity, respectively). 


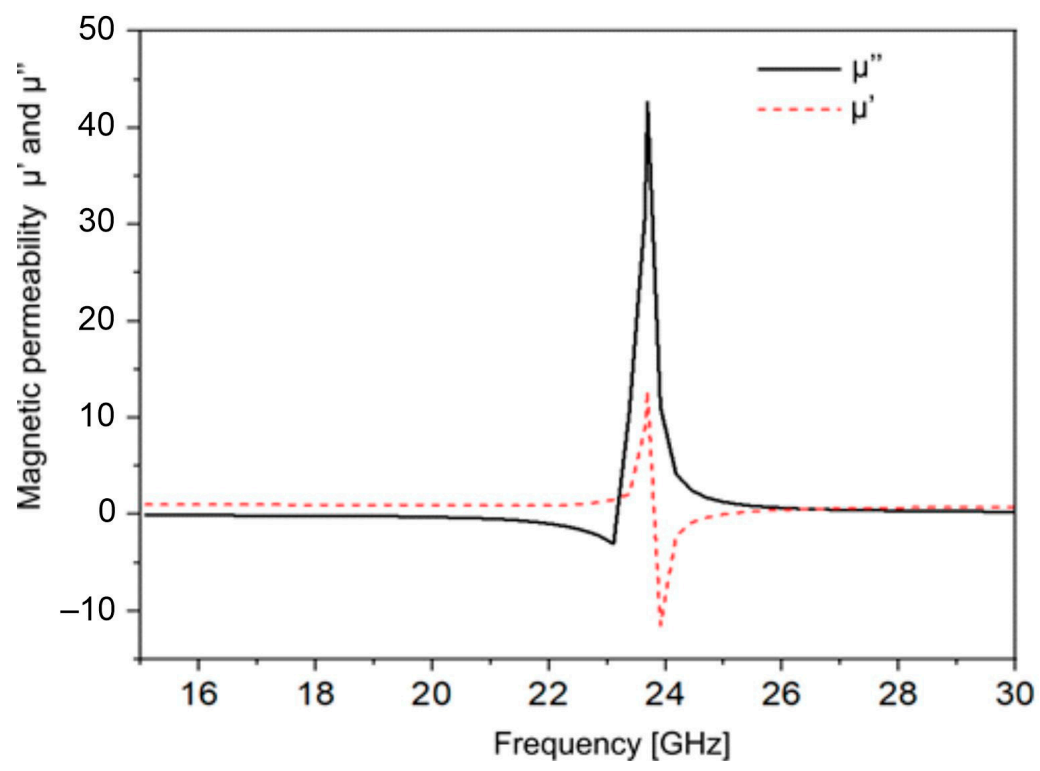

Figure 4. Frequency characteristics of the composite magnetic permeability of the tested SRR structure ( $\mu^{\prime}$ and $\mu^{\prime \prime}$, the real and imaginary parts of the effective electric permeability, respectively).

Figure 5 shows the frequency characteristics of the coefficients for reflection $\mathrm{R}$, transmission $\mathrm{T}$, and absorption A of the studied metasurface in the frequency range of $15-30 \mathrm{GHz}$. As can be seen, the absorption coefficient A of the studied metasurface in the whole frequency range was zero, because the SRR structures were made of the perfect (lossless) conductor, in which conductivity was zero.

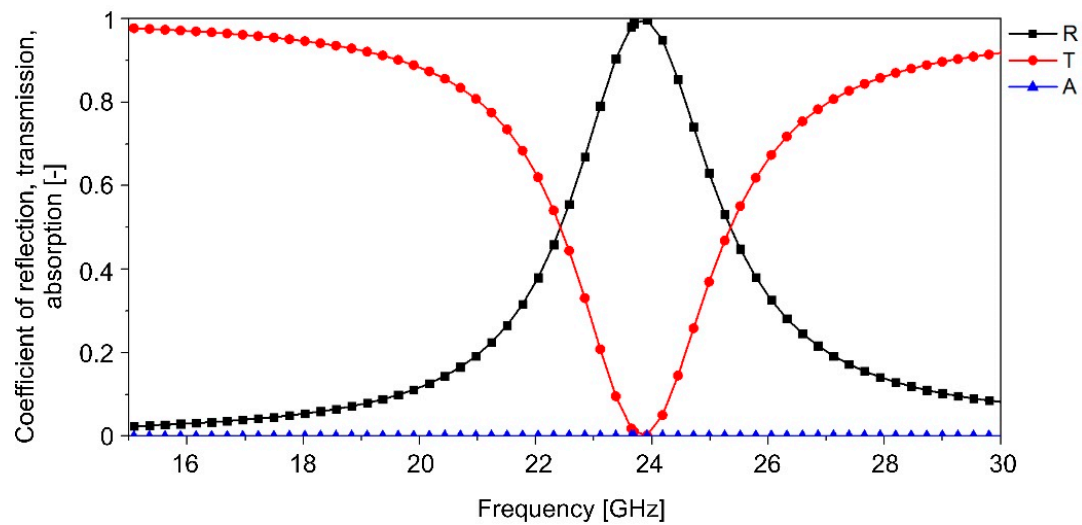

Figure 5. Coefficients of reflection (R), transmission (T), and absorption (A) of the electromagnetic radiation of the metasurface as a function of frequency.

Figure 5 also shows one relatively wide reflection band of the tested metasurface within the 15 to $30 \mathrm{GHz}$ range. The reflection phenomenon results from the near-field coupling-induced magnetic response [63]. The transmission coefficient $\mathrm{T}$ of the EM wave has a minimal value (practically zero) for this frequency; therefore, $23.69 \mathrm{GHz}$ is the resonant frequency of the studied metasurface.

At the resonance frequency of $23.69 \mathrm{GHz}$ and during one wave period, the spatial distributions of electric and magnetic fields in the computational area surrounding the examined SRR structure were determined in the time domain. Then, we were able to trace the interaction of the incident plane wave with the examined SRR structure for the single wave period. Figures 6 and 7 present the vector distributions of the electric field in the xy plane and the magnetic field in the xz plane. They confirm that, for the frequency $\mathrm{f}=23.69 \mathrm{GHz}$ corresponding to the magnetic resonance, there is a total reflection of the incident wave from the SRR structure. As illustrated in Figures 6 and 7, the EM field behind 
the SRR structure is practically zero during the single wave period. In contrast, at the front of the SRR resonator, an EM standing wave with clearly visible node points for the electric and magnetic waves is formed by the interference of the wave incident on the SRR structure with that reflected from it. Figures 6 and 7 show that the distance between the nodes of the electric and magnetic waves equals approximately $3.18 \mathrm{~mm}$, i.e., a quarter of the wavelength of the incident plane wave. Therefore, it confirms that the calculated EM field in front of the SRR structure is a standing wave. The above clearly indicates that the examined SRR structure totally reflects the EM plane wave incident on it, just like an infinite plane from a perfect conductor. Thus, the temporal and spatial distribution of the EM fields, as presented in Figures 6 and 7, visualize the interaction between the incident EM wave and the SRR structure during one wave period. This interaction is a total reflection of the incident wave off the SRR structure. Therefore, the SRR structure behaves similar to an almost perfect reflector at the resonant frequency of $23.69 \mathrm{GHz}$.

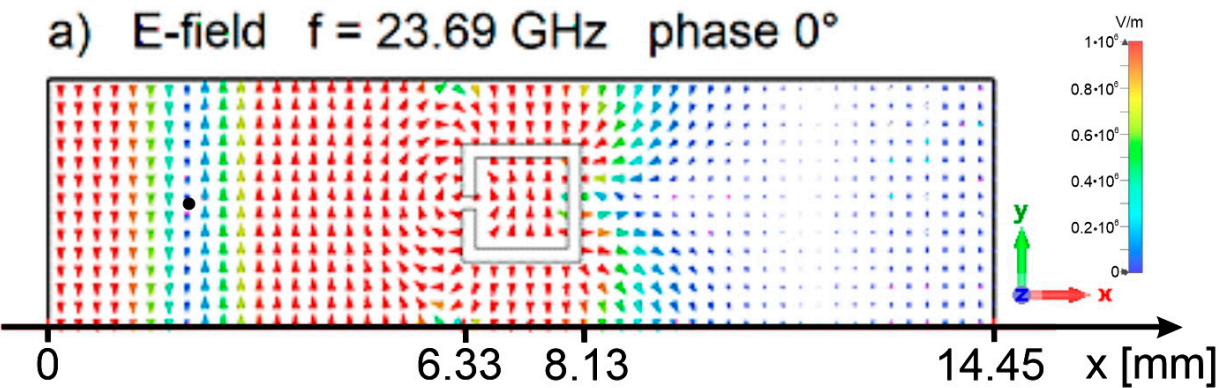

\section{b) E-field $f=23.69 \mathrm{GHz}$ phase $90^{\circ}$}

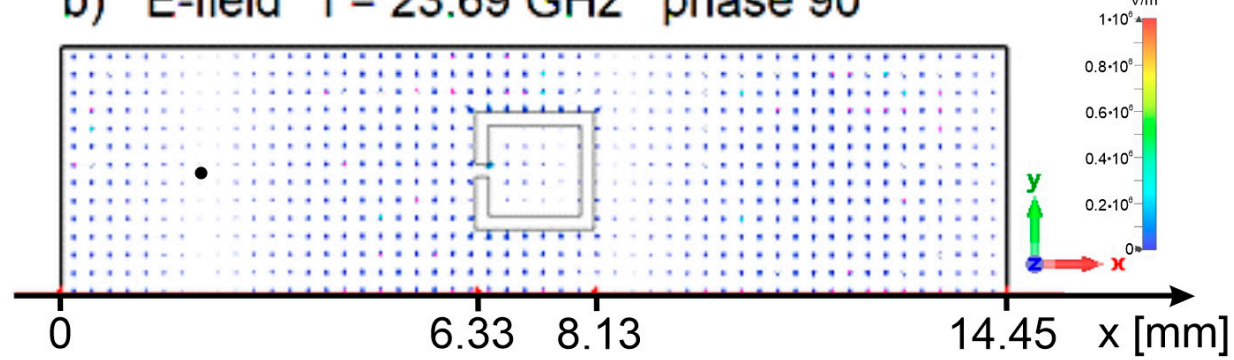

\section{c) E-field $f=23.69 \mathrm{GHz}$ phase $180^{\circ}$}

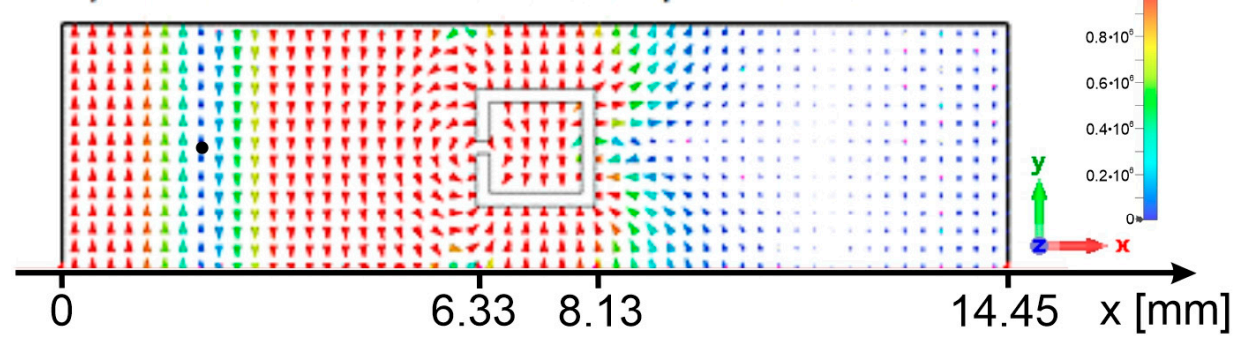

\section{d) E-field $f=23.69 \mathrm{GHz}$ phase $270^{\circ}$}

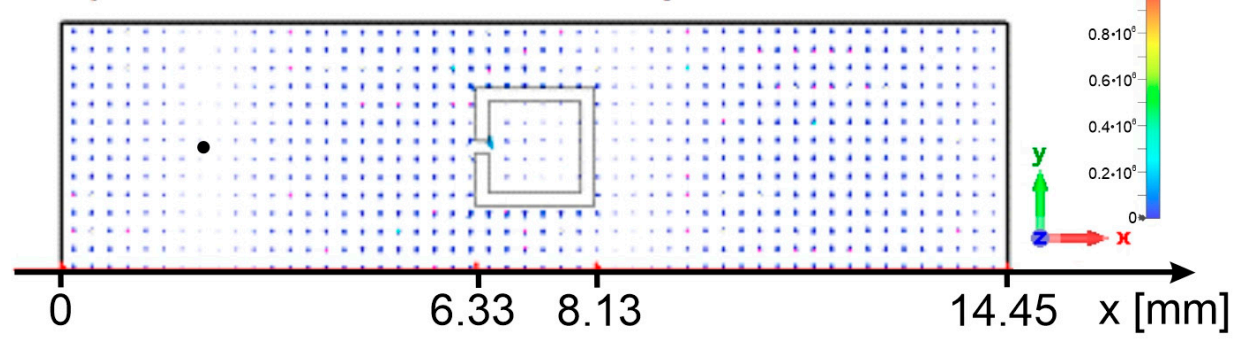

Figure 6. Distribution of the electric field $\mathrm{E}$ in the cross-sections $\mathrm{xy}$ for $\mathrm{z}=-1.6 \mathrm{~mm}$ at $\mathrm{f}=23.69 \mathrm{GHz}$ corresponding to the magnetic resonance. The plane electromagnetic wave propagates in the $+x$ axis: (a) Phase $0^{\circ}$; (b) phase $90^{\circ}$; (c) phase $180^{\circ}$; (d) phase $270^{\circ}$. Black points, the nodes of the standing wave. 


\section{a) $\mathrm{H}$-field $f=23.69 \mathrm{GHz}$ phase $0^{\circ}$}

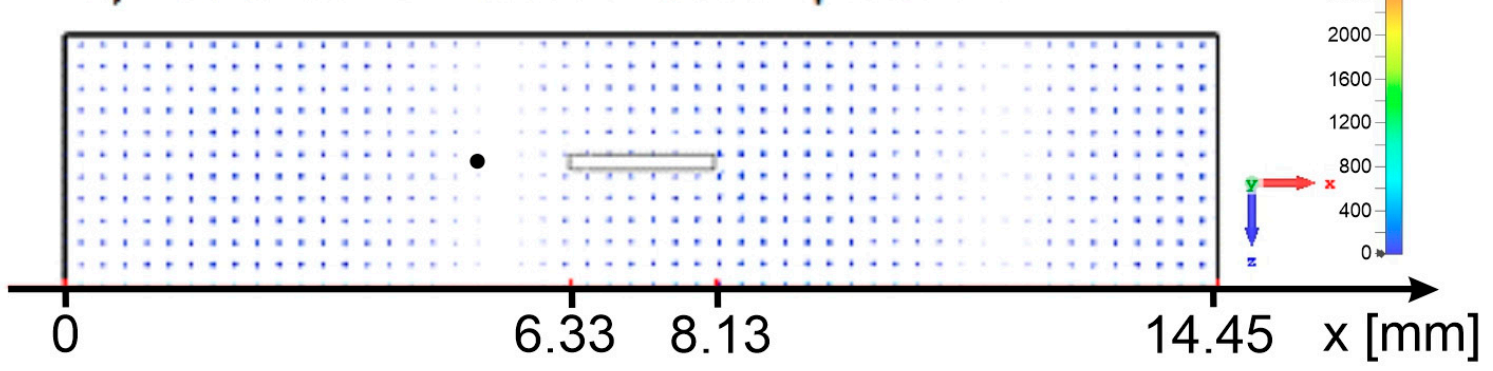

b) $\mathrm{H}$-field $\mathrm{f}=23.69 \mathrm{GHz}$ phase $90^{\circ}$

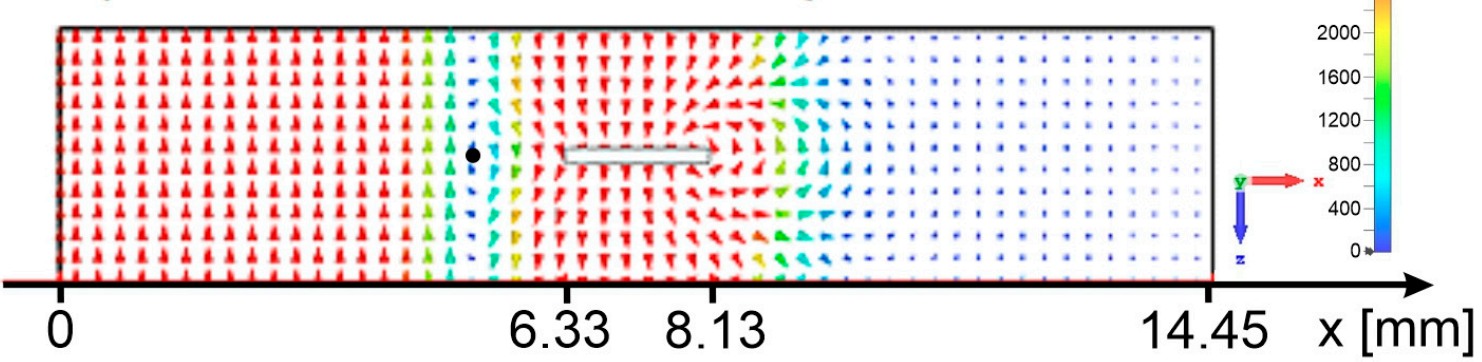

c) $\mathrm{H}$-field $\mathrm{f}=23.69 \mathrm{GHz}$ phase $180^{\circ}$

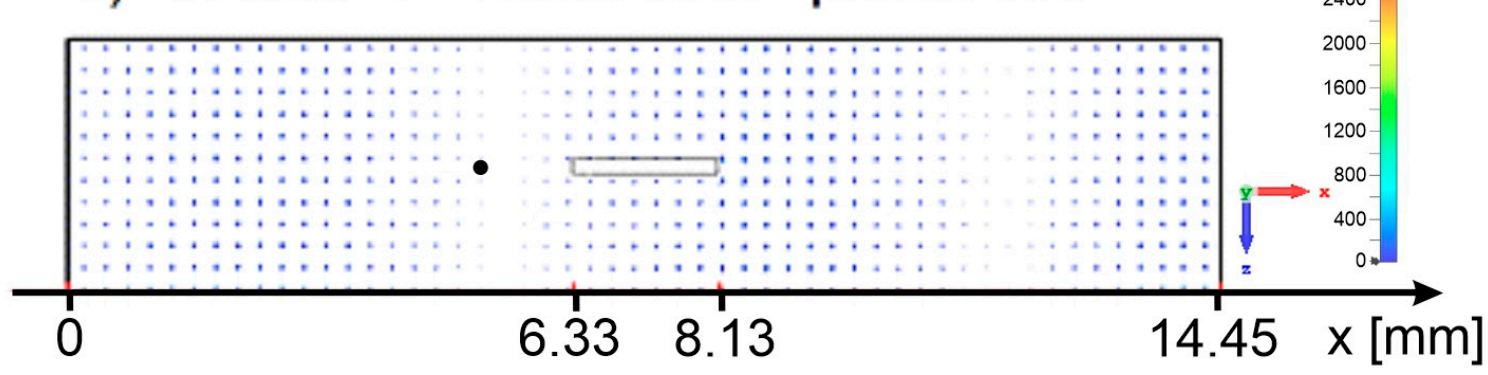

d) $\mathrm{H}$-field f $=23.69 \mathrm{GHz}$ phase $270^{\circ}$

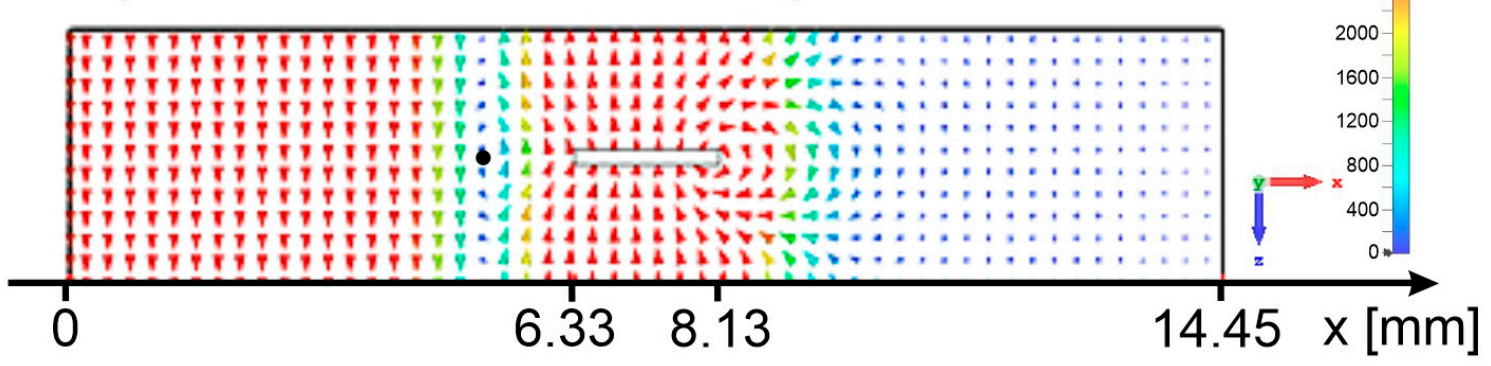

Figure 7. Distribution of the magnetic field $\mathrm{H}$ in the cross-sections $\mathrm{xz}$ for $\mathrm{y}=1.9 \mathrm{~mm}$ at $\mathrm{f}=23.69 \mathrm{GHz}$ corresponding to the magnetic resonance. The plane electromagnetic wave propagates in the $+x$ axis: (a) Phase $0^{\circ}$; (b) phase $90^{\circ}$; (c) phase $180^{\circ}$; (d) phase $270^{\circ}$. Black points, the nodes of the standing wave.

We repeated the same time-domain procedures, as described above, to visualize the interaction of the incident plane wave with the examined SRR structure at a frequency different from the resonant frequency. The detuned frequency was $21 \mathrm{GHz}$. According to the numerical calculations of the coefficients $\mathrm{R}$ and $\mathrm{T}$, presented in Figure 5, $\mathrm{R}=19 \%$ and $\mathrm{T}=81 \%$. That is, upon detuning from the resonant frequency to $21 \mathrm{GHz}$, the wave 
incident on the SRR structure results in partial reflection (19\%) and transmission (81\%). The results of the time-domain simulations, as shown in Figures 8 and 9, visualize this effect. As clearly seen from Figures 8 and 9, at the detuned frequency $21 \mathrm{GHz}$, the electric and magnetic waves propagate through the SRR structure in the $x$-direction, and there are no (fully) standing electric and magnetic waves in front of the SRR structure.

a) E-field $f=21.00 \mathrm{GHz}$ phase $0^{\circ}$

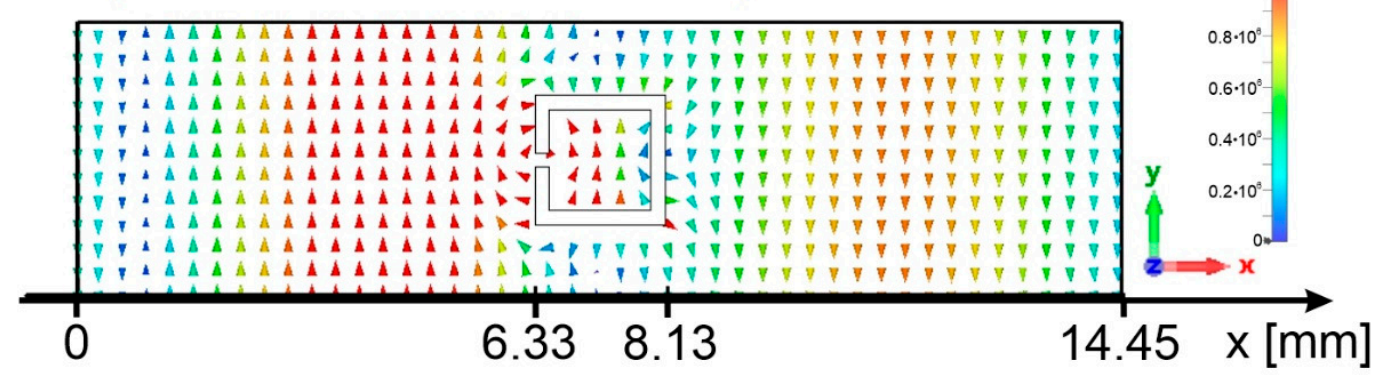

b) E-field $f=21.00 \mathrm{GHz}$ phase $90^{\circ}$

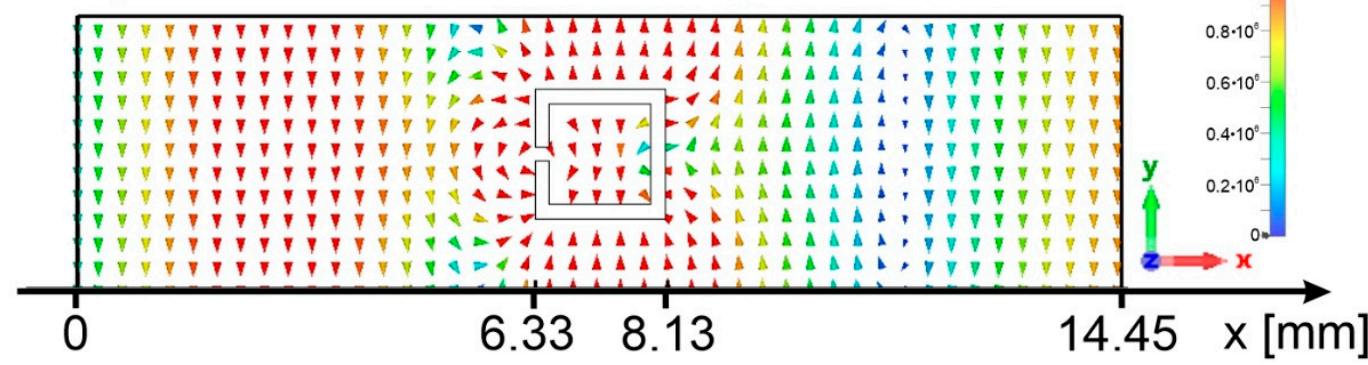

c) E-field $f=21.00 \mathrm{GHz}$ phase $180^{\circ}$

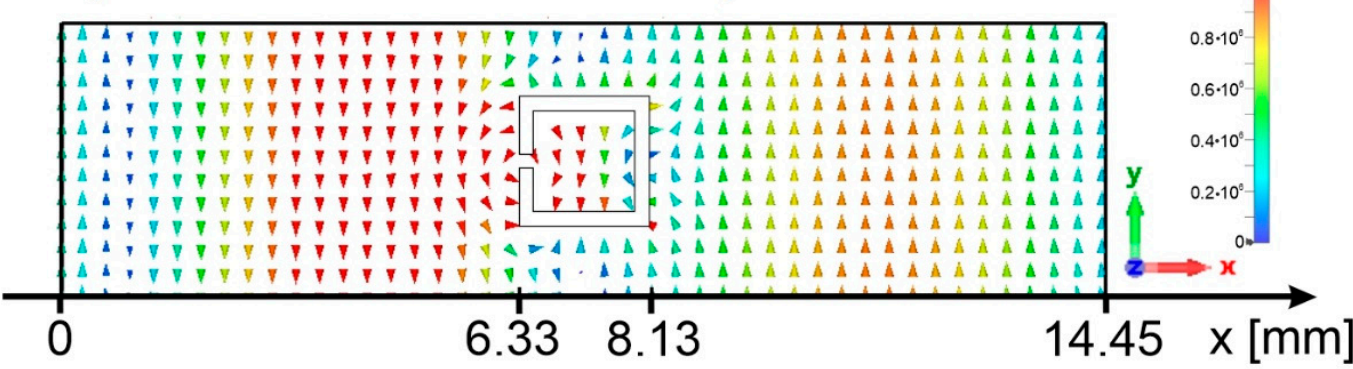

d) E-field $f=21.00 \mathrm{GHz}$ phase $270^{\circ}$

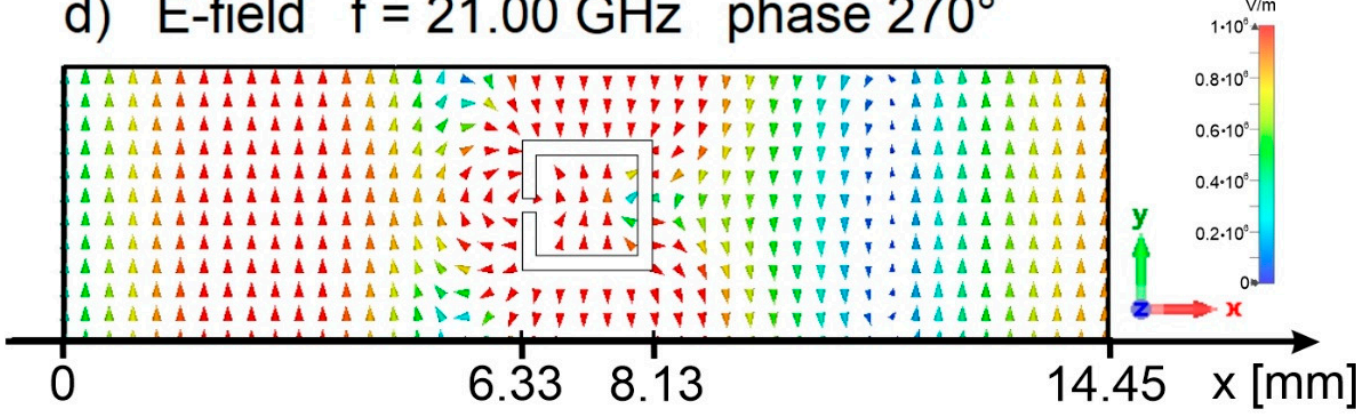

Figure 8. Distribution of the electric field $E$ in the cross-sections $x y$ for $z=-1.6 \mathrm{~mm}$ at $\mathrm{f}=21 \mathrm{GHz}$ corresponding to the detune magnetic resonance. The plane electromagnetic wave propagates in the +x axis: (a) Phase $0^{\circ}$; (b) phase $90^{\circ}$; (c) phase $180^{\circ}$; (d) phase $270^{\circ}$. The wave incident on the SRR structure results in partial reflection $(19 \%)$ and transmission $(81 \%)$. 


\section{a) $\mathrm{H}$-field $\mathrm{f}=21.00 \mathrm{GHz}$ phase $0^{\circ}$}

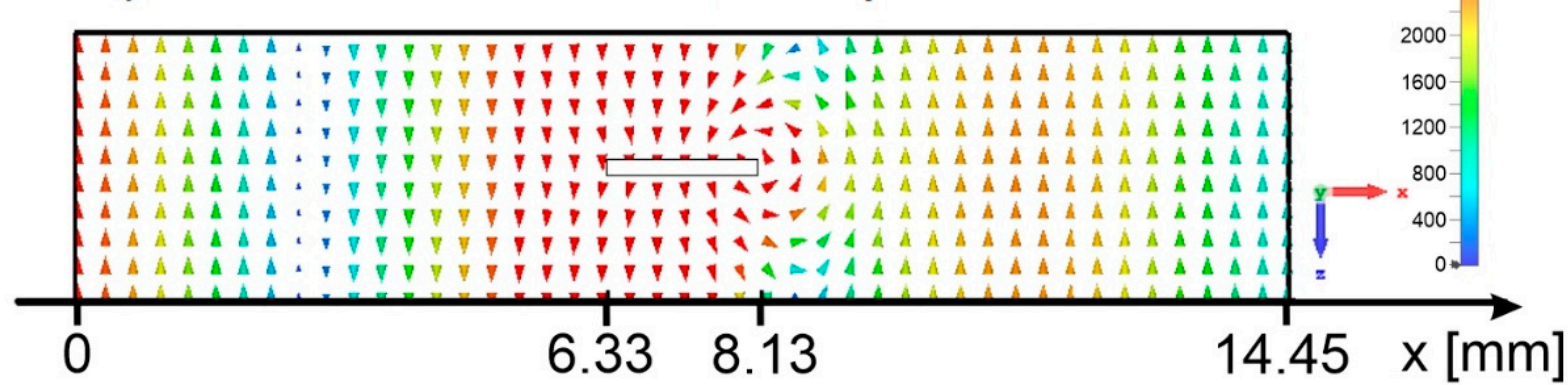

\section{b) $\mathrm{H}$-field $\mathrm{f}=21.00 \mathrm{GHz}$ phase $90^{\circ}$}

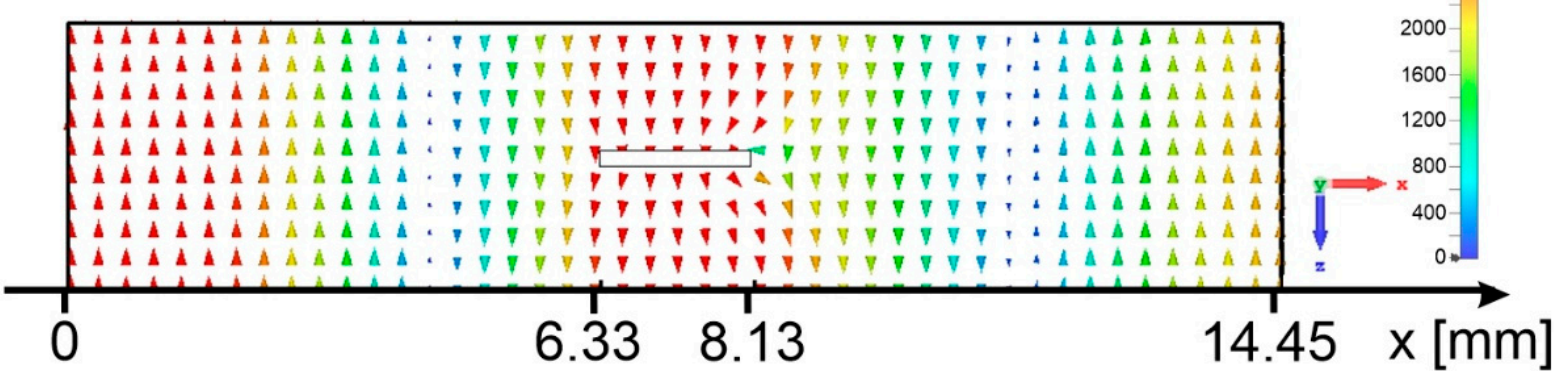

\section{c) $\mathrm{H}$-field $\mathrm{f}=21.00 \mathrm{GHz}$ phase $180^{\circ}$}

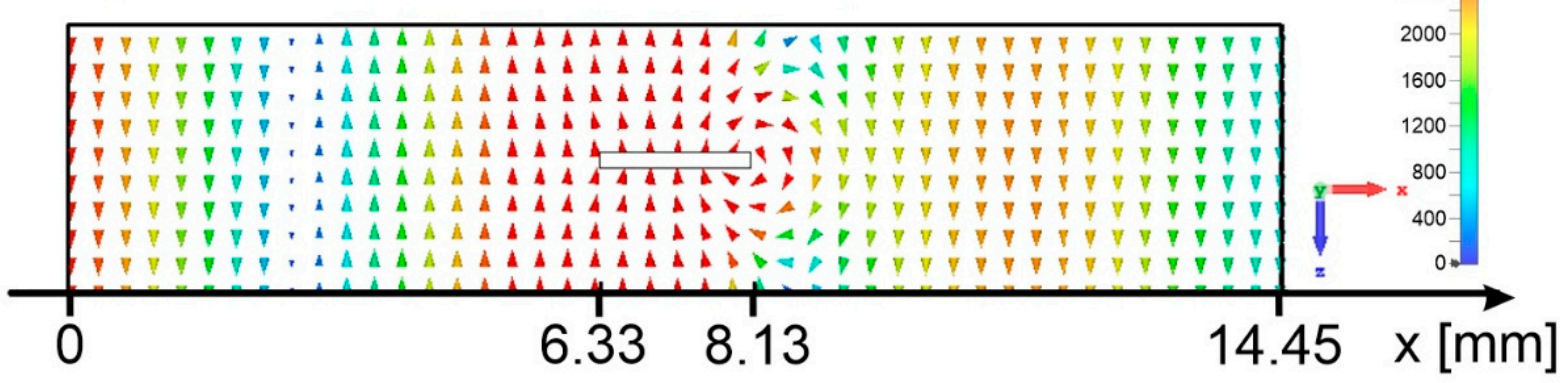

d) $\mathrm{H}$-field $\mathrm{f}=21.00 \mathrm{GHz}$ phase $270^{\circ}$

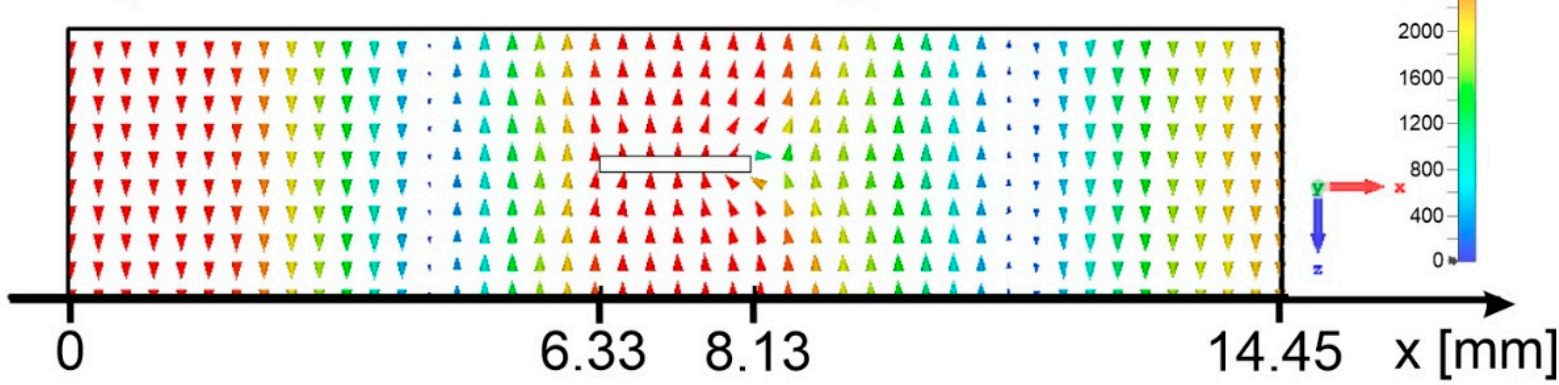

Figure 9. Distribution of the magnetic field $\mathrm{H}$ in the cross-sections $x z$ for $y=1.9 \mathrm{~mm}$ at $\mathrm{f}=21 \mathrm{GHz}$ corresponding to the detune magnetic resonance. The plane electromagnetic wave propagates in the +x axis: (a) Phase $0^{\circ}$; (b) phase $90^{\circ}$; (c) phase $180^{\circ}$; (d) phase $270^{\circ}$. The wave incident on the SRR structure results in partial reflection $(19 \%)$ and transmission $(81 \%)$.

Figures 5-8 show the electric field concentrated in the gap of the SRR for both the resonant and detuned frequencies [64]; this is from the accumulation of charges due to the 
circular electric current. In contrast, the magnetic field is concentrated around the ring The difference between the resonance and detuned cases is the magnitude of the charge accumulated in the gap, i.e., the charge is greater in the resonance case.

\section{Conclusions}

The numerical simulation, using CST Studio, of the interaction between EM radiation and a split-ring resonator showed that the examined SRR structure demonstrated reflectivetransmission properties in the range of $15-30 \mathrm{GHz}$ with the magnetic resonance at the frequency of $\mathrm{f}=23.69 \mathrm{GHz}$. At the resonance, the SRR shows the ability to fully reflect the EM wave. This leads us to conclude that structures similar to that examined in this study can be used as strong reflectors in antenna systems for wireless telecommunications.

In this study, the phenomenon of total reflection of the EM wave by the examined SRR structure was successfully visualized by $2 \mathrm{D}$ vector maps of the electric and magnetic fields around the SRR structure during the wave period. Confirming the numerical calculations performed, at the resonance, the vector-field visualization showed no EM field behind the SRR structure and the standing electric and magnetic waves before the SRR structure. In this study, the vector-field visualization of the SRR structure response at the detuned frequency was also performed to better understand the interaction of the EM wave with the SRR structure. The visualizations presented in this study are both unique educational presentations to help understand the interaction of EM plane waves with the SRR structure of the reflection characteristics at the magnetic resonance and detuned frequencies.

Author Contributions: Conceptualization, M.B. and J.M.; methodology, M.B. and J.M.; investigation, M.B. and J.M.; writing—original draft preparation, M.B. and J.M.; writing-review and editing M.B. and J.M.; visualization, M.B., S.R. and J.M.; supervision, M.B. and J.M. All authors have read and agreed to the published version of the manuscript.

Funding: The project was financed within the program of the Ministry of Science and Higher Education called "Regionalna Inicjatywa Doskonałości" in 2019-2022; the project number was 006/RID/2018/19 and the total financing was PLN 11,870,000.

Institutional Review Board Statement: Not applicable.

Informed Consent Statement: Not applicable.

Conflicts of Interest: The authors declare no conflict of interest.

\section{References}

1. Kennedy, D. Breakthrough of the year: The runners-up. Science 2004, 302, 2033-2034. [CrossRef]

2. Capolino, F. Applications of Metamaterials; CRC Press: Boca Raton, FL, USA, 2009.

3. Gay-Balmaz, P.; Martin, O.J. Electromagnetic resonances in individual and coupled split-ring resonators. J. Appl. Phys. 2002, 92, 2929-2936. [CrossRef]

4. Oliveri, G.; Werner, D.H.; Massa, A. Reconfigurable electromagnestics through metamaterials-A review. Proc. IEEE 2015, 103, 1034-1056. [CrossRef]

5. Liu, X.; Zhao, Q.; Lan, C.; Zhou, J. Isotropic Mie resonance-based metamaterial perfect absorber. Appl. Phys. Lett. 2013, 103, 031910. [CrossRef]

6. Xiong, X.; Jiang, S.C.; Hu, Y.H.; Peng, R.W.; Wang, M. Structured metal film as a perfect absorber. Adv. Mater. 2013, 25, 3994-4000. [CrossRef] [PubMed]

7. Guangsheng, D.; Hanxiao, S.; Kun, L.; Jun, Y.; Zhiping, Y.; Baihong, C. 3D-Printed Multiband Absorber Based on Stereo Frequency Selective Structures. Phys. Status Solidi 2021, 218, 7.

8. Qinyu, Q.; Chinhua, W.; Li, F.; Liwen, C.; Haitao, C.; Liang, Z. An ultra-broadband metasurface perfect absorber based on the triple Mie resonances. Opt. Mater. 2021, 116, 111103.

9. Niu, T.; Qiu, B.; Zhang, Y.; Hirakawa, K. Control of absorption properties of ultra-thin metal-insulator-metal metamaterial terahertz absorbers. Jpn. J. Appl. Phys. 2020, 59, 12. [CrossRef]

10. Jianli, C.; Hongcheng, X.; Xiaohua, Y.; Guirong, S.; Huixia, S. A Novel Encoding Strategy of Enhanced Broadband and Absorption Conformable Metamaterial for MW Applications. IEEE Access 2020, 8, 100458-100468.

11. Feng, L.; Huo, P.; Liang, Y.; Xu, T. Photonic Metamaterial Absorbers: Morphology Engineering and Interdisciplinary Applications. Adv. Mater. 2019, 32, 27. [CrossRef] 
12. Nahvi, E.; Liberal, I.; Engheta, N. Nonlinear metamaterial absorbers enabled by photonic doping of epsilon-near-zero metastructures. Phys. Rev. B 2020, 102, 3. [CrossRef]

13. Zahra, S.; Ma, L.; Wang, W.; Li, J.; Chen, D.; Liu, Y.; Zhou, Y.; Li, N.; Huang, Y.; Wen, G. Electromagnetic Metasurfaces and Reconfigurable Metasurfaces: A Review. Front. Phys. 2021, 8, 615. [CrossRef]

14. Haixia, M.; Wang, X. Wide-angle broadband near-perfect all-dielectric metamaterial reflector. Opt. Eng. $2018,57,017102$.

15. Slovick, B.; Yu, Z.G.; Berding, M.; Krishnamurthy, S. Perfect dielectric-metamaterial reflector. Phys. Rev. B 2013, 88, 165116. [CrossRef]

16. Xu, W.; Sonkusale, S. Microwave diode switchable metamaterial reflector/absorber. Appl. Phys. Lett. 2013, 103, 031902. [CrossRef]

17. Badloe, T.; Mun, J.; Rho, J. Metasurfaces-based absorption and reflection control: Perfect absorbers and reflectors. J. Nanomater. 2017, 2017, 1-18. [CrossRef]

18. Keshavarz, A.; Vafapour, Z. Sensing avian influenza viruses using terahertz metamaterial reflector. IEEE Sens. J. 2019, 19, 5161-5166. [CrossRef]

19. Suakaew, J.; Pijitrojana, W. A Dynamic Wireless Power Transfer Using Metamaterial-Based Transmitter. Prog. Electromagn. Res. C 2021, 110, 151-165. [CrossRef]

20. Cho, Y.; Lee, S.; Kim, D.-H.; Kim, H.; Song, C.; Kong, S.; Park, J.; Seo, C.; Kim, J. Thin hybrid metamaterial slab with negative and zero permeability for high efficiency and low electromagnetic field in wireless power transfer systems. IEEE Trans. Ind. Electron. 2018, 60, 4. [CrossRef]

21. Wang, B.; Nishino, T.; Teo, K.H. Wireless Power Transmission Efficiency Enhancement with Metamaterials. In Proceedings of the 2010 IEEE International Conference on Wireless Information Technology and Systems, Honululu, HI, USA, 28 August-3 September 2010.

22. Wang, B.; Teo, K.H.; Nishino, T.; Yerazunis, W.; Barnwell, J.; Zhang, J. Wireless Power Transfer with Metamaterials. In Proceedings of the 5th European Conference on Antennas and Propagation (EUCAP), Rome, Italy, 11-15 April 2011.

23. Landy, N.I.; Sajuyigbe, S.; Mock, J.J.; Smith, D.R.; Padilla, W.J. Perfect metamaterial absorber. Phys. Rev. Lett. 2008, 100, 207402. [CrossRef] [PubMed]

24. Almoneef, T.S.; Ramahi, O.M. Metamaterial electromagnetic energy harvester with near unity efficiency. Appl. Phys. Lett. 2015, 106, 153902. [CrossRef]

25. Zhong, H.T.; Yang, X.X.; Tan, C.; Yu, K. Triple-band polarization-insensitive and wide-angle metamaterial array for electromagnetic energy harvesting. Appl. Phys. Lett. 2016, 109, 253904. [CrossRef]

26. Zhong, H.T.; Yang, X.X.; Song, X.T.; Guo, Z.Y.; Yu, F. Wideband metamaterial array with polarization-independent and wide incident angle for harvesting ambient electromagnetic energy and wireless power transfer. Appl. Phys. Lett. $2017,111,213902$. [CrossRef]

27. Fang, N.; Zhang, X. Imaging Properties of a Metamaterial Superlens. In Proceedings of the 2nd IEEE Conference on Nanotechnology, Washington, DC, USA, 28 August 2002.

28. Wong, Z.J.; Wang, Y.; O’Brien, K.; Rho, J.; Yin, X.; Zhang, S.; Zhang, X. Optical and acoustic metamaterials: Superlens, negative refractive index and invisibility cloak. J. Opt. 2017, 19, 084007. [CrossRef]

29. Haxha, S.; AbdelMalek, F.; Ouerghi, F.; Charlton, M.D.B.; Aggoun, A.; Fang, X.J.S.R. Metamaterial superlenses operating at visible wavelength for imaging applications. Sci. Rep. 2018, 8, 1-15. [CrossRef]

30. Li, H.; Zhang, Y.; He, L. Tunable Filters Based on the Varactor-Loaded Spilt-Ring Resonant Structure Coupled to the Micropstrip Line. In Proceedings of the International Conference on Microwave and Millimeter Wave Technology (ICMMT ‘08), Nanjing, China, 21-24 April 2008.

31. Bouyge, D.; Crunteanu, A.; Pothier, A.; Martin, P.O.; Blondy, P.; Velez, A.; Bonache, J.; Orlianges, J.C.; Martin, F. Reconfigurable 4 Pole Bandstop Filter Based on RF-MEMS-Loaded Split Ring Resonators. In Proceedings of the IEEE MTT-S International Microwave Symposium (MTT ‘10), Anaheim, CA, USA, 23-28 May 2010.

32. Ghafari, S.; Forouzeshfard, M.R.; Vafapour, Z. Thermo optical switching and sensing applications of an infrared metamaterial. IEEE Sens. J. 2019, 20, 3235-3241. [CrossRef]

33. Vafapour, Z. Polarization-independent perfect optical metamaterial absorber as a glucose sensor in Food Industry applications. IEEE Trans. Nanobiosci. 2019, 18, 622-627. [CrossRef]

34. Xia, L.; Wang, Y.; Wang, G.; Long, X.; Huang, S.; Tan, Y.; Yan, W.; Dang, S.; Yiun, S.; Cui, H. Graphene based terahertz amplitude modulation with metallic tortuous ring enhancement. Opt. Commun. 2019, 440, 190-193. [CrossRef]

35. Vafapour, Z. Slow light modulator using semiconductor metamaterial. Proc. SPIE 2018, 10535, 105352A.

36. Wang, G.; Lu, H.; Liu, X. Dispersionless slow light in MIM waveguide based on a plasmonic analogue of electromagnetically induced transparency. Opt. Express 2012, 20, 19. [CrossRef] [PubMed]

37. Pekka, A.; Tretyakov, S. Electromagnetic cloaking with metamaterials. Mater. Today 2009, 12, 22-29.

38. Yang, S.; Liu, P.; Yang, M.; Wang, Q.; Song, J.; Dong, L. From flexible and stretchable meta-atom to metamaterial: A wearable microwave meta-skin with tunable frequency selective and cloaking effects. Sci. Rep. 2016, 6, 1-8. [CrossRef] [PubMed]

39. Montoya, J.A.; Tian, Z.B.; Krishna, S.; Padilla, W.J. Ultra-thin infrared metamaterial detector for multicolor imaging applications. Opt. Express 2017, 25, 23343-23355. [CrossRef] [PubMed]

40. Mohamadi, T.; Yousefi, L. Metamaterial-based energy harvesting for detectivity enhanced infrared detectors. Plasmonics 2019, 14, 815-822. [CrossRef] 
41. Tao, H.; Padilla, W.J.; Zhang, X.; Averitt, R.D. Recent progress in electromagnetic metamaterial devices for terahertz applications. IEEE J. Selected Topics Quantum Electron. 2011, 17, 1. [CrossRef]

42. Langley, R.; Liu, L.; Lee, H.-J.; Ford, L. Tunable Antennas and AMC Structures. In Proceedings of the IEEE Antennas and Propagation Society International Symposium, Toronto, ON, Canada, 11-17 July 2010.

43. Yan, L.B.; Zhu, W.M.; Wu, P.C. Adaptable metasurface for dynamic anomalous reflection. Appl. Phys. Lett. 2017, 110, 20. [CrossRef]

44. Grigonienè, J.; Karnauskas, M. Mathematical modeling of optimal tilt angles of solar collector and sunray reflector. Energetika 2009, 1, 41-46.

45. Zhu, B.; Feng, Y.; Zhao, J.; Huang, C.; Jiang, T. Switchable metamaterial reflector/absorber for different polarized electromagnetic waves. Appl. Phys. Lett. 2010, 97, 5. [CrossRef]

46. ETSI EN 302 217-1 V1.1.4. Fixed Radio Systems; Characteristics and Requirements for Point-to-Point Equipment and Antennas, European Standard (Telecommunications Series); European Telecommunications Standards Institute: Sophia Antipolis, France, 2005.

47. Pendry, J.B.; Holden, A.J.; Stewart, W.J.; Youngs, I. Extremely low frequency plasmons in metallic mesostructured. Phys. Rev. Lett. 1996, 76, 4773. [CrossRef]

48. Pendry, J.B.; Holden, A.J.; Stewart, W.J.; Youngs, I. Low frequency plasmons in thin-wire structures. J. Phys. Condens. Matter 1998, 10, 4785-4809. [CrossRef]

49. Smith, D.R.; Padilla, W.J.; Vier, D.C.; Nemat-Nasser, S.C.; Schultz, S. Composite Medium with Simultaneously Negative Permeability and Permittivity. Phys. Rev. Lett. 2000, 84, 4184-4187. [CrossRef] [PubMed]

50. Shelby, R.A.; Smith, D.R.; Schultz, S. Experimental Verification of a Negative Index of Refraction. Science 2001, 292, 77-79. [CrossRef] [PubMed]

51. Yoo, Y.J.; Yi, C.; Hwang, J.S.; Kim, Y.J.; Park, S.Y.; Kim, K.W.; Lee, Y. Experimental realization of tunable metamaterial hypertransmitter. Sci. Rep. 2016, 6, 1-8.

52. Cakir, M.; Cakir, G.; Sevgi, L. A Two-Dimensional FDTD-Based Virtual Visualization Tool for Metamnaterial-Wave Interaction. IEEE Antennas Propag. Mag. 2008, 50, 166-175. [CrossRef]

53. Grande, A.; González, O.; Pereda, J.A.; Vegas, Á. Educational Computer Simulations for Visualizing and Understanding the Interaction of Electromagnetic Waves with Metamaterials. In Proceedings of the IEEE EDUCON 2010 Conference, Madrid, Spain, 14-16 April 2010; pp. 543-547.

54. Wielichowski, M.; Mosig, J.R. A MATLAB-Based Virtual Tool for Visualizing the Plane Wave Propagation in Multilayer Structures Containing Metamaterials. In Proceedings of the 2012 6th European Conference on Antennas and Propagation (EUCAP), Prague, Czech Republic, 26-30 March 2012; pp. 1-4.

55. Pekmezci, A.; Sevgi, L. FDTD-based Metamaterial (MTM) Modeling and Simulation. IEEE Antennas Propag. Mag. 2014, 56, 289-303. [CrossRef]

56. Katsarakis, N.; Koschny, T.; Kafesaki, M. Electric coupling to the magnetic resonance of split ring resonators. Appl. Phys. Lett. 2004, 84, 2943-2945. [CrossRef]

57. CST Studio Suite. Available online: www.cst.com (accessed on 5 November 2021).

58. Nicolson, A.M.; Ross, G.F. Measurement of the intrinsic properties of materials by time-domain techniques. IEEE Trans. Instrum. Meas. 1970, 19, 377-382. [CrossRef]

59. Weir, W.B. Automatic measurement of complex dielectric constant and permeability at microwave frequencies. Proc. IEEE 1974, 62,33-36. [CrossRef]

60. Rothwell, E.J.; Frasch, J.L.; Ellison, S.M.; Chahal, P.; Ouedraogo, R.O. Analysis of the Nicolson-Ross-Weir Method for Characterizingthe Electromagnetic Properties of Engineered Materials. Prog. Electromagn. Res. 2016, 157, 31-47. [CrossRef]

61. Caloz, C.; Itoh, T. Electromagnetic Metamaterials: Transmission Line Theory and Microwave Applications: The Engineering Approach; John Wiley \& Sons: Hoboken, NJ, USA, 2006.

62. Pendry, J.B.; Holden, A.J.; Robbins, D.J.; Stewart, W.J. Magnetism from conductors and enhanced nonlinear phenomena. IEEE Trans. Micr. Theory Tech. 1999, 47, 2075-2084. [CrossRef]

63. Min-Yeong, Y.; Sungjoon, L. Switchable Electromagnetic Metamaterial Reflector/Absorber. In Proceedings of the Asia Pacific Microwave Conference Proceedings, Kaohsiung, Taiwan, 4-7 December 2012; pp. 445-447.

64. Tingting, L. Active Manipulation of Electromagnetically Induced Transparency in a Terahertz Hybrid Metamaterial. Opt. Commun. 2018, 426, 629-634. 